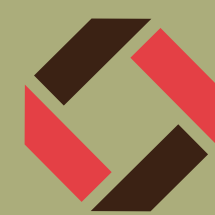

\title{
Janglin Chen's return to Taiwan brings display vision to fruition
}

\section{Prachi Patel}

$\mathbf{A}^{\prime}$ t 8:00 p.m. on a cold spring evening in 2006, Janglin Chen sat in his study, anxious and dejected. After 24 years as a chemist at Kodak, years which he had dedicated to creating breakthrough commercial products for the company, the future looked uncertain.

Kodak wanted to sell its display film business, and some of the research groups in that unit, including Chen's, were trying to negotiate a spin-off. Chen and his colleagues had flown to Asia to meet with potential investors, but the negotiations had not gone well. "I was very disappointed and went back to Rochester [NY]," Chen recalled. "I got there about 6:00 p.m.; my wife picked me up from the airport. After dinner, I went to my study thinking, what's next?" Then the phone rang.

It was a friend from Taiwan's Industrial Technology Research Institute (ITRI) who Chen had not talked with in years. The ITRI, a nonprofit research institution, had tried to recruit Chen before, but with a kid in school and an advancing career at Kodak, the time had never been right. His friend now had a new offer. The institution was undergoing a major reshuffle, combining laboratories and forming various technology focus centers. They wanted Chen to lead their brand new Display Technology Center. This time, Chen accepted.

"All these doors had been closing on me and now all of a sudden here was a door someone else opened," Chen said. "The display sector is very vital to Taiwan's economy. I loved the challenge. And another important reason is that my mother is getting old and, with the long distance, I hadn't been the good son I used to be. I decided it was time to move back to my native land."

A few weeks later, nearly 24 years to the day after he had joined Kodak, Chen left for Taiwan. He is happy to be back home, and in just five years, his acumen and vision have earned ITRI international recognition and multiple awards. The unplanned move to Taiwan, he said, has turned out to be "the best thing that's happened to me." And, in some ways, the shift exemplifies Chen's career, which has evolved every few years, leading each time to success.

Chen was born and raised in Kaohsiung, Taiwan. He received his bachelor's degree in 1975 from Tsing Hua University, where he met his wife Cindy, also a chemistry student. They married after Chen's mandatory military stint, and came to the United States for graduate school at what was then the Polytechnic Institute of New York in Brooklyn (it is now part of New York University). Chen obtained his $\mathrm{PhD}$ degree in polymer chemistry in 1982, and landed a job as a chemist at Kodak.

His first project as an eager young researcher was to come up with an antistatic agent for medical x-ray films. "At that time, $x$-ray films were prone in winter to static charge," Chen said. "When charge accumulated to a certain degree the films would spark and this resulted in a bright spot in the image, which could lead to misdiagnosis." He came up with a robust, low-cost coating for the films based on a solid electrolyte. The accomplishment led to an Outstanding Innova- tion Award in 1985 and a promotion to technical group leader.

For his next challenge, he collaborated with scientists at rival Fujifilm. Their goal: to modernize conventional 35-mm photography so it could compete with emerging digital camera technology. The researchers created a film with a magnetic memory coating on the back that recorded data on critical camera and environmental settings, which a technician could later use to improve or restore images. The film was popular between 1995 and 2000, but, said Chen, "the end of the story was a bit sour. Not too long after the product launched, the digital camera became really popular."

For Chen, as for Kodak, this signaled a need to branch out in a new direction: displays. In doing so, Kodak was emu-

At Taiwan's Industrial Technology Research Institute, Janglin Chen eads the Display Technology Center. 
scene, Fuji had a stronghold on polarizer protector films for flat-panel displays (it still holds over $80 \%$ of the market share). "We spent a lot of time and put a lot of money into trying to catch up with Fuji, but to no avail," Chen said. "We were unfortunately too late and too little. Also by then much of the display manufacturing was shifting from the Western world to the east."

Kodak's decision to bow out of the display business eventually led to Chen's return to his home country. He is now vice president and general director of ITRI's display center.

In keeping with the institute's goal to lead Taiwanese manufacturers in research by three to five years, Chen directed the center's researchers into the uncharted territory of flexible displays when he took the helm. Glass screens are brittle, heavy, and power-hungry, and he believes that cell phones and laptops of the future will need more portable and energy-efficient displays. "There's going to be a day when flexible displays are popular," Chen said. "They are lightweight, thin, unbreakable, bendable or even rollable, very easy to store and carry. They show the beauty of how material chemists contribute to the electronics industry."

The move came as a shock to his research staff, mostly electrical engineers with minimal materials experience. But it has paid off. Under Chen's direction, the researchers have invented a simple, low-cost method that could enable the mass manufacture of paper-like color screens. Last year, the technology won an R\&D 100 award and the overall Gold in the Wall Street Journal Technology Innovation Award.

The challenge with making bendable displays is that high electronics processing temperatures melt the plastic substrates. The ITRI technique hinges on a new type of polymer sheet that withstands $300^{\circ} \mathrm{C}$ temperatures and remains clear after chemical treatments.

The researchers coat the plastic on glass and then fabricate electronics on it. Inspired by traditional Taiwanese crepe making, they have come up with an organic nonstick material with which they pretreat the glass, and which allows them to later smoothly peel away the entire display from the glass. ITRI is now transferring this technology to Taiwanese display panel manufacturers.

"We're using mainstream facilities to make flexible displays," Chen said. "Using this technique, you could adapt any process that used to be based on silicon wafer or glass."

Chen's team is also working on new types of flexible liquid-crystal displays (LCDs) called cholesteric LCDs. These,

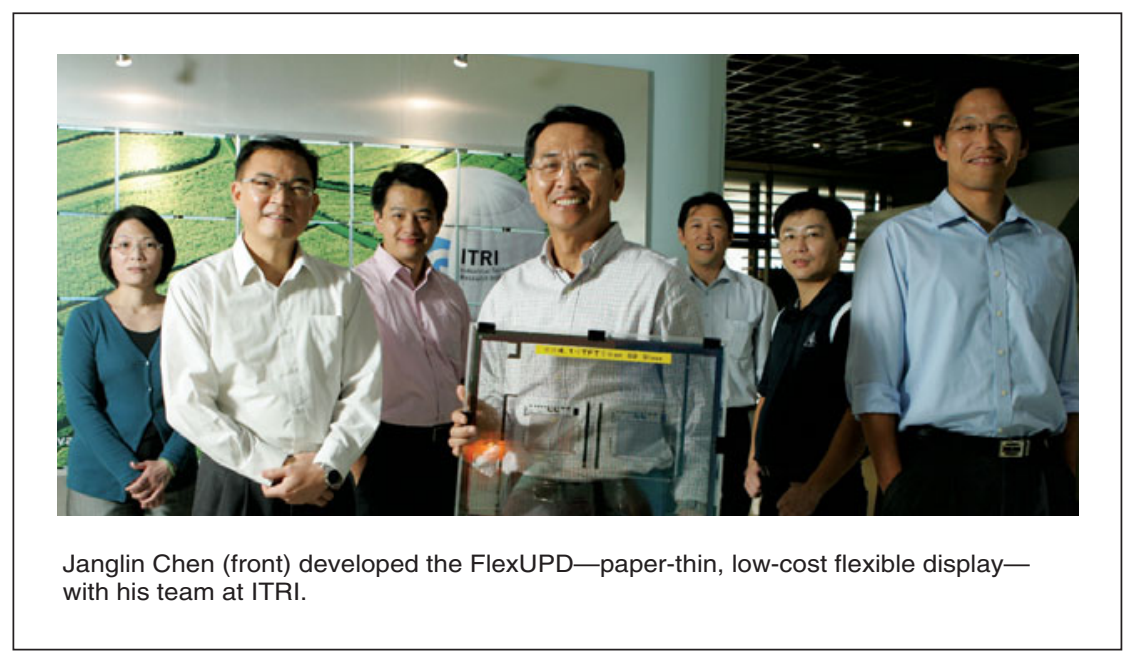

unlike today's e-paper technologies, do not require color filters and could lead to brighter screens that render more real color. The researchers have made a cholesteric LCD that is capable of showing video, and are now working on making the display using roll-to-roll manufacturing techniques. Chen and his team have won another WSJ Technology Innovation Award and R\&D 100 award for a rewritable e-paper based on flexible cholesteric LCDs. The product uses heat instead of ink for writing, and stores the image without requiring electricity.

Another exciting area of ongoing research is electrowetting display technology. This can be used to make energy-saving smart windows that are electrically controlled to the amount of light passing through.

Chen considers himself fortunate to have worked at two very different organizations in two very different countries, and finds it easy to bridge the two cultures. In fact, he has kept in touch with friends in Rochester, and transferred intellectual property and equipment from Kodak to ITRI for the rewritable e-paper. "Being bilingual and bicultural are among the best things I could have," he said. "I had a great career at Kodak and now I'm lucky to have a career that's even more fascinating and more rewarding." 

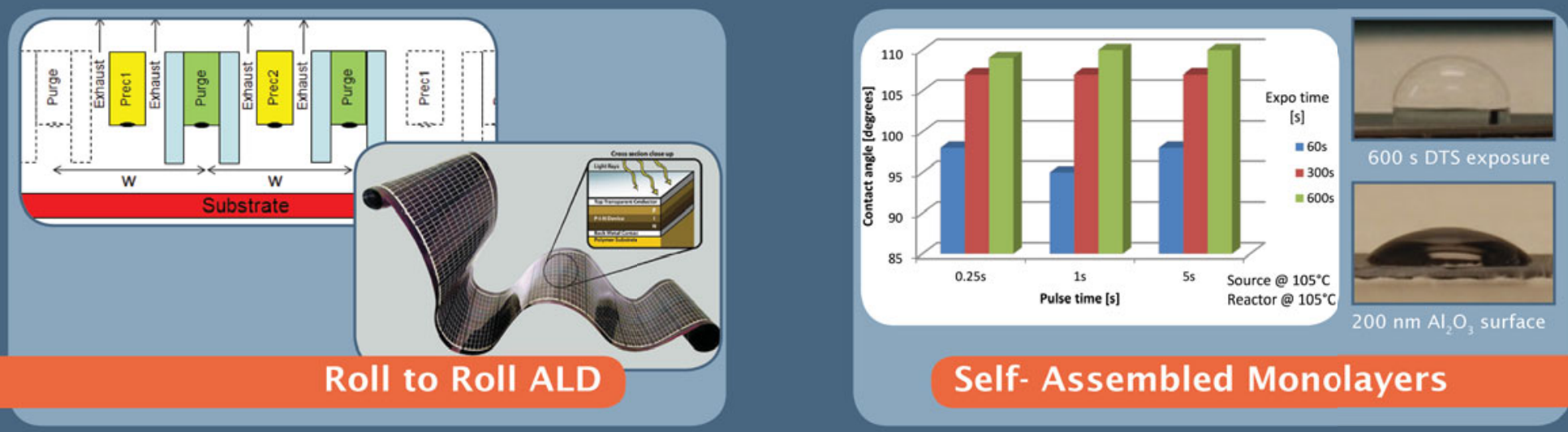

\section{Self- Assembled Monolayers}
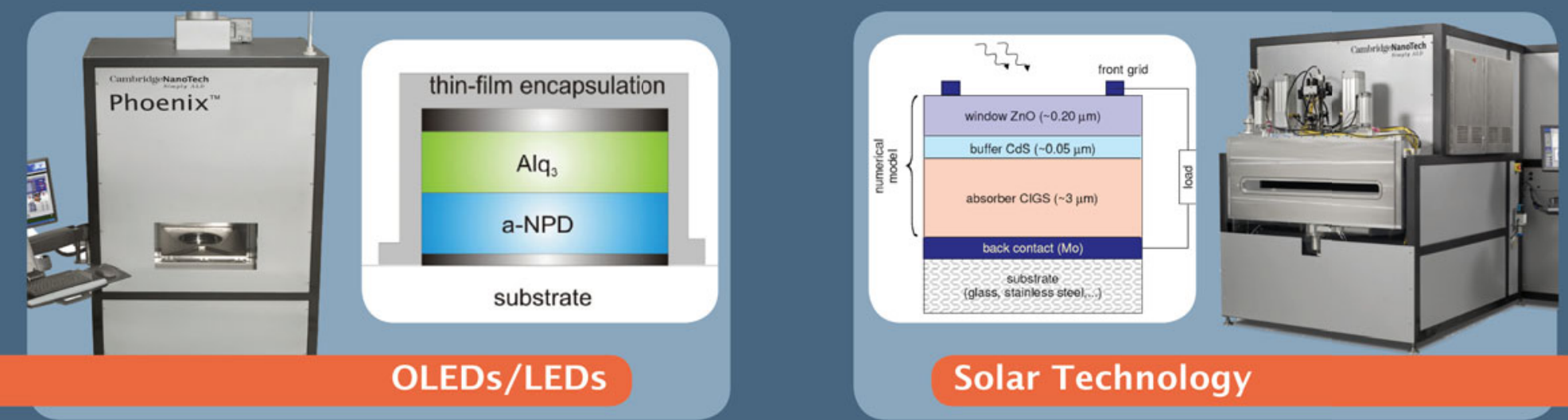

\section{Solar Technology}
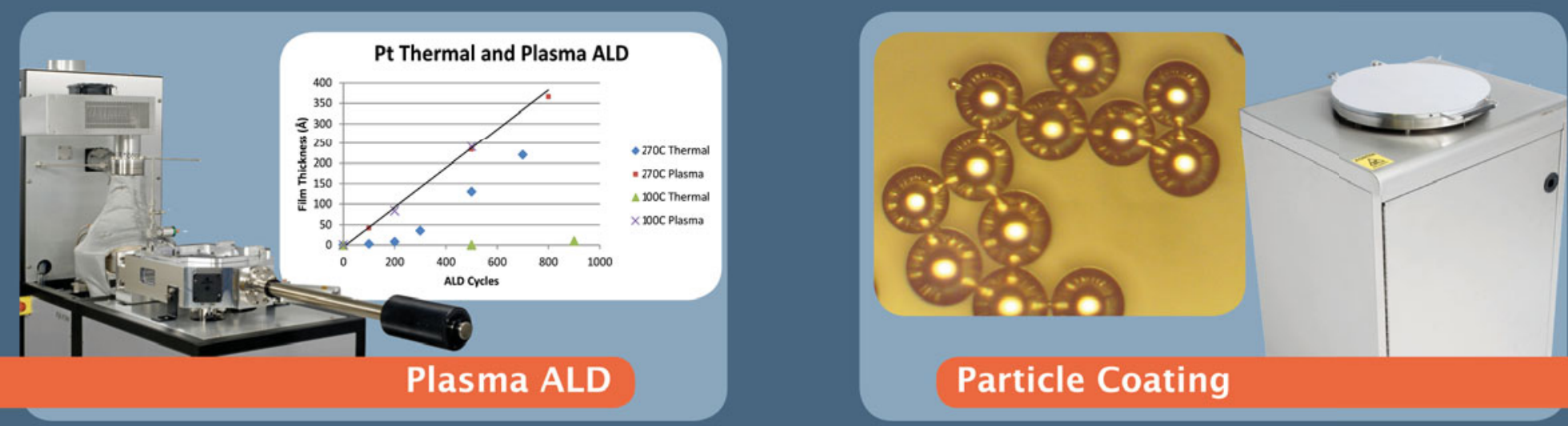

\section{Particle Coating}

\section{Taking your innovations from ordinary to extra-ordinary one layer at a time.}

With over 250 systems shipped for research and development, Cambridge NanoTech is the leading ALD supplier to academic and industrial institutions worldwide. From accelerating the speed of semiconductors to improving the efficiency of solar panels, ALD holds tremendous promise across a wide array of industries, including energy, optical, electronics, nanostructures, biomedical, and more.
Cambridge NanoTech

Simply $A L D$ 